\title{
The Vudec merger: a recording of what was and a reflection on gains and losses
}

\author{
H. M. van der Merwe \\ Department of Further Teacher Education \\ University of South Africa \\ Pretoria, South Africa \\ e-mail:vdmerhm@unisa.ac.za
}

\begin{abstract}
The restructuring of higher education in South Africa is being dually steered by an equity and a merit imperative. In the move towards creating a single dedicated distance-education institution, the outcome of the merged incorporation of Vista University Distance Education Campus (Vudec) into the University of South Africa (UNISA) implied the obliteration of the Vudec culture. This has warranted the recording of the Vudec culture based on the valid need to document the existence of an institution of higher education over a period of 21 years. It has also warranted an assessment of gains and losses as a result of the merger. Based on literature and a qualitative study undertaken in Vudec, the Vudec institutional culture has been documented and gains and losses for Vudec students and staff determined. It is argued that although significant gains were made, such as better opportunities for students and staff due to improved resources, a serious loss has been incurred in the disappearance of the under-developed student corps of practising teachers. Apart from not fully accomplishing the equity goal, this loss also jeopardises merit achievements.
\end{abstract}

\section{INTRODUCTION}

At the end of the apartheid era in 1994 the quality of South African higher education institutions differed significantly across racial lines with historically black institutions falling far behind the historically white universities with regard to funding, facilities and international reputation (NCHE 1996, 9-23). The postapartheid government acknowledged the internationally competitive research and teaching capacities of the historically white universities and stressed the exploitation of their expertise and infrastructure by means of a restructuring process (Education White Paper 3 1997, 8).

Mergers promise a more efficient, system-wide management of educational resources, the opportunity for moral and political redress and the ideal of better learning outcomes for all students (Elliot 2005, 71; Reddy 2000, 80). In the light of the fit between these potential advantages and the ideals of a restructured South African higher education landscape, it was inevitable that mergers would become legally determined as proclaimed by the Higher Education Act 101 of 1997 (RSA 1997, 22). 
Based on the recommendations of the Council on Higher Education (CHE 2000, 44-45), the establishment of a single dedicated distance-education institution was announced on 5 March 2001 as outcome 11 of the National Plan on Higher Education (NPHE 2001, sec. 4.5). This outcome determined the unitary merger of the Vista University Distance Education Campus (Vudec), the University of South Africa (UNISA) and the Technikon South Africa (TSA). In practice this constituted the incorporation of Vudec into UNISA, followed by the merger between UNISA and TSA.

The rationale for the establishment of a single dedicated distance-education institution was based on the imperative of equity through access and the imperative of merit through economic efficiency (Elliot 2005, 69; Jansen 2003, 32; Ntshoe $2004,142)$. The apartheid legacy was to be addressed by increased access to higher education by previously deprived students within the context of a competitive global economy. Against the backdrop of this dual agenda January 2004 saw the merged incorporation of Vudec into UNISA.

\section{RATIONALE FOR STUDY AND RESEARCH DESIGN}

Within the context of the merit imperative for the restructuring of the South African higher education landscape, the merger of Vudec and UNISA was inevitable due to decreasing student numbers at both Vudec and UNISA and the institutions' overlapping offering of similar programmes in similar fields. From the point of view of equity, Vudec's exclusive targeting of previously disadvantaged black students needed redress. Inevitably this merger had to lead to the absorption, to the point of obliteration, of the smaller institution in terms of size and reputation and which was also a creation of apartheid, by UNISA which enjoys mega status.

Although acknowledging the possibility of an atheoretical posture of peculiarities of a specific case, Vudec's culture was to disappear in the merger and therefore required recording to ensure documentation of the 21 years of existence of a higher education institution within the annals of the history of South African higher education. In light of government's promises of reaching equity through mergers, this record is followed by a reflection on the position of Vudec staff and students within the merged environment. This article therefore focuses on addressing two questions: What was the role, function and characteristics of Vudec? What have Vudec staff and students gained and lost through the merger?

Data was gathered by archival search and interviews. Three in-depth individual interviews and two semi-structured focus group interviews were conducted with fifteen purposefully selected participants. Selection was based on the participants' engagement with Vudec for more than five years. This enabled the collection of data from veteran informants with both depth and breadth experience of involvement with Vudec (Johnson 2002, 106). In-depth individual interviews with the three participants in management positions contributed to an accurate understanding from their point of view (Cohen, Manion and Morrison 2002). Two 
focus group interviews were conducted, one with seven participants from the academic staff and one with five participants from the corps of postgraduate students enrolled in the humanities. The value of participants' checks and balances through interaction in the focus group interview was richly obtained and enhanced the quality of data gathered (Patton 2001, 386). Inductive analysis based on the model of Tesch was used to ensure that all perspectives and issues arising from the data were included in the report (De Vos 1998, 343). Guba's trustworthiness model was employed to establish the validity and reliability of the qualitative research in terms of truth-value, applicability, consistency and neutrality (De Vos 1998, 348350). The anonymity of participants and confidentiality of their disclosures were guaranteed at all times during the research.

\section{MERGING - A THEORETICAL BACKGROUND}

Mergers occur regularly in higher education as a way of national government initiatives to realise systemic restructuring. To name but a few, countries like Australia, Canada, Norway, Great Britain, Germany and New Zealand have been affected by such change (Curri 2002; Harman 2002; Lang 2002; Norgard and Skodvin 2002). Influenced by the globalisation features of policy borrowing between countries and the notion of sharing appropriate forms and contents (Christy 1996, 156; Lang 2002, 11; Ntshoe 2003, 382), higher education mergers in South Africa have also occurred on account of government's demand for fewer, larger and more effective and efficient universities (Harman and Meek 2002, 1). The implication is that a consensus on size for desired effect presupposes common outcomes based on common motives and common formations.

\section{Merger formations}

On a continuum of possible formations of higher education mergers, a federation of almost complete institutional autonomy represents one pole and amalgamation with a complete loss of identity, the other pole. In between, different formations are identifiable, such as, among others, protected enclosure and subsumed integration (Jansen 2003, 35). With subsumed integration the 'take-over' of a smaller, vulnerable institution into a larger, established institution is implied (Jansen 2003, 36).

A complete amalgamation, which is the focus of this study, represents the merging of two separate institutions into a single new organisational entity for the sake of survival within a changed environment (Goedegebuure 1992, 16, 105). Complete amalgamation is accompanied by the demand for a unitary structure with a single identity (Botha 2001, 278) which reflects either a horizontal character whereby merging institutions operate in similar fields offering similar programs, or a vertical character whereby the offerings are in different programs within a similar field (Lang 2002, 25). When a single identity is determined, the one institution gets 
absorbed by the other without the absorbing institution being dramatically affected (Elliot 2005, 75; Lang 2002, 25). The dominant institution, true to generic logic, is the larger one with the more profound history (Curri 2002, 146).

In evolving into a single identity, the minor institution ceases to exist as a legal entity and all its assets, liabilities and responsibilities, including the human element, are transferred. The implication is very often a total obliteration of the minor institution's culture (Goedegebuure 1992, 16; Harman 2002, 94) with significant effects on staff who must adapt to new physical and psychological environments. The effect on staff as determined in the South African context include negative feelings of loss, insecurity and frustration; positive feelings hold the prospect of fresh thinking, new ways and extended networks (Hay, Fourie and Hay 2001; Jansen 2002; Wyngaard and Kapp 2004).

\section{Motives for merging}

Throughout the history of higher education, the motives for higher education mergers have related to the expectations of the different stakeholders. In general, government has always expected the provision of skilled personpower for economic development; the private sector has always relied on the delivery of a specific quality of skill; professions have always depended on employees with an academically oriented schooling; students and their parents have always expected a profound preparation for a successful future; and the general public has always presupposed a significant impact on the improvement of human life (Louw 1997, 43). These expectations have always represented an equity demand as connoted by general public anticipation and a merit demand as connoted by the rest of stakeholder anticipations.

Manifestations of the merit demand such as increased efficiency and effectiveness is to be found in government actions of dealing with non-viable institutions, institutional fragmentation and the improvement of the quality of graduates for a competitive world market (Harman and Meek 2002, 1). In this regard institutional fragmentation is counteracted by the financial dividend in that unit costs are cut, economies of scale are achieved and an unnecessary duplication of programmes are rationalised. Strategically, merging holds a competitive advantage of improving management skills by replacing inefficient managers (Botha 2001, 275) and by improving academic and administrative capacity (Hay et al. 2001, 101). The enhancement of academic capacity by creating a strong research culture is significantly high on the international agenda for merging (Harman 2002, 92). An interesting consequence of the latter is the development of 'academic capitalism' in that individual academics with eminent research records increasingly act as state-subsidised entrepreneurs that expend their human capital stock in competitive situations (Ntshoe 2004, 139).

Manifestations of the equity demand in terms of widened access presuppose the integration of different student cultures to level differences that relate to history, 
culture, language and geography (Lang 2002, 26). Widened access may also manifest in differentiated course offerings to provide for greater student diversity. This, in turn, may hold a merit motive of penetration of new markets, the developing of new products and services and the acquiring of new capabilities and resources (Botha 2001, 276; Harman and Meek 2002, 1).

Merit and equity as stakeholder expectations of higher education have remained relevant. So has the arranging of government control to realise these objectives (Harman and Meek 2002, 1; Lang 2002, 10). What has changed, however, is the transformation to a situation in which global markets and global technologies dominate government policy inclinations. With regard to higher education reform, this has resulted in a neo-liberal approach of favouring the unrestricted role of markets in society to the expense of democratic practice in public policy (Kenway 1996, 220; Ntshoe 2003, 383; Weber 2002, 265). Within the sphere of higher education mergers for the sake of merit and equity, this results in a dominance of the merit motive over the equity motive with the possibility of achieving equity only after economic efficiency has successfully been realised (Elliot 2005, 73; Lang 2002, 17).

\section{Outcomes of mergers}

Against the background of merit and equity as unequal components in an economic doctrine of macro-political decision-making, contingency theory relates to an interpretation of merger outcomes within a transitional context. Contingency theory proclaims outcomes to be conditioned by and contingent on the specific forms of interaction between institutional micro-politics and governmental macropolitics (Jansen 2003, 29; Sehoole 2005, 160). Final effects of merging are only visible after ten years of merging (Hay et al. 2001, 102). However, transitional effects may be identified with regard to equity, efficiency, the curriculum, organisational matters, students, staff and physical aspects.

\section{The rationale for merging in the South African context}

Impelled by an electoral mandate to reverse the inherited inequities and inequalities, the post-apartheid government needed a post-apartheid education policy with access, equity and redress at its ideological vanguard. However, this had to be achieved within a context of global market demand for efficiency and effectiveness. An urgent need was to reverse the socio-political embarrassment of ill-performing institutions without hampering the international prestige of the academically prominent universities that had developed international networks of scholarship and funding before 1994. In this regard, Jansen (2005) argues that, for example, the University of Pretoria should insist on remaining a world-class research university built on a curriculum and culture that is unashamedly global, inclusive and competitive. 
It appeared obvious that the default motive guiding higher education mergers should be politically inclined towards equity through redress because 'redress is a useful term at the outset of any restructuring period' (Elliot 2005, 73). Based on the Reconstruction and Development Programme (RDP), official policy claims were indeed congruent with equitable, socially just redistribution expectations (CHE 2000; DoE 2002: Education White Paper 3 1997). The 1996 Growth Employment and Redistribution (GEAR) policy, however, introduced merit as the dominant motive for government actions based on competitive outward-oriented economic growth (Ntshoe 2004; Weber 2002). Understood against this developmental background and within the sphere of global influences on South African policy-making, it makes sense that government's motives with mergers as initiated since 2001, in the final instance, relate to merit and financial survival (Hay et al. 2001, 106; Jansen 2003, 38). For that reason programmes and institutions that could not deliver economic efficiency were to be abandoned under the guise of social welfare (Elliot 2005; Weber 2002).

The merger of Vudec and UNISA implied a total absorption of the Vudec staff and students into related departments housed at UNISA's Muckleneuk campus. The physical incorporation took place at the beginning of 2004. Staff of the agricultural and environmental science departments remained at the Vudec building to amalgamate with corresponding TSA departments. As opposed to the absence of forceful governmental steering as was seen in the incorporation of the South African College for Teacher Education (SACTE) into UNISA (Jansen 2003, 49), the role of government in the Vudec-UNISA merger has been positive and assertive. For instance, the merging of the two autonomous national institutions had to take place on equal terms according to specified deadline dates. This resulted in a well-planned, fair and humane albeit subsumed integration of the smaller vulnerable Vudec by the larger established UNISA. On account of the merger's horizontal character and UNISA's magnitude in terms of sheer numbers and competencies, the curriculum of Vudec was largely ignored and Vudec students and staff officially became full-fledged UNISA members participating in UNISA programmes. This implied the swift disappearance of the Vudec identity which provided the imperative to this research: firstly to preserve the Vudec institutional culture for historical purposes on account of 21 years of constructive existence and secondly, to determine which aspects of the Vudec identity was worth accommodating in the merger.

\section{WHAT WAS THE ROLE, FUNCTION AND CHARACTERISTICS OF VUDEC?}

Based on a synthesis of the archival data and the findings of the qualitative investigation, the narration of the Vudec culture is presented according to four themes. Findings are substantiated by verbatim excerpts from the interviews. 


\section{Establishment}

In 1978 the Nationalist government appointed a commission of inquiry into the tertiary needs of urban black people. Based on its recommendations Vista University was established in January 1982 to meet the significant needs of black urban students (Vista University Calendar 2003, 8). The initial motive with Vudec's establishment was thus a racially oriented political motivation, expressed as follows by a Vudec academic:

Vista University was established during the heyday of the apartheid era to serve especially black students whom government did not want in the former white universities and could not all hide in the universities of the so-called homelands.

However, the political motive turned out to be inadvertently accompanied by the merit motive of affordability, convenience and coherence. A Vudec manager explained:

Vista University was intended to serve the needs of urban black South Africans. We were no longer expected to go to the desolated black universities in the homelands. By avoiding additional costs like transport and accommodation, higher education became easier attainable, affordable, and friendlier, on our doorsteps.

Besides reducing transport and accommodation expenses, student fees at Vista University were considerably less than those at other universities. This distinguished Vista University's niche as not only serving a specific racial group within specific geographical areas, but serving also 'the expectations of a specific income group' (Vudec manager). The consequence was that the initial negatively loaded rationale for establishment, namely racial segregation, over time produced significant benefits for the black communities in terms of attainable higher education opportunities and thus, social mobility.

Vista University constituted a multi-campus character consisting of seven contact tuition campuses and one distance tuition campus. These campuses were located in main urban areas: the Bloemfontein campus, the East Rand campus at Daveyton Springs, the Mamelodi campus at Pretoria, the Port Elizabeth campus, the Sebokeng campus at Vanderbijlpark, the Soweto campus, the Welkom campus and the VUDEC campus at Skinner Street, Pretoria.

Vudec, the distance education campus, was the first to be established in April 1982. Initially known as Vista University Further Training campus, its purpose lay in assuming the function of teacher education from the department responsible for the education of black learners, that is, the Department of Education and Training. In 1998 its name changed to Vista University Distance Education Campus, that is, Vudec (Vista University Calendar 3002, 8). 


\section{Student profile and curriculum offerings}

When established in 1982 Vudec's initial purpose was to offer diploma and certificate courses to under-qualified, practising black teachers with the aim of a qualification upgrade to effect eventual entry into graduate studies (Vista University Calendar 3002, 8). This niche market continued and at the time of incorporation Vudec was still catering for practising black teachers. However, the offerings expanded to include first degree and honours degree courses and advanced certificates in education.

Owing to the niche market of teacher upgrade, the majority of Vudec students registered in the Faculty of Education. In 2003, the last year of Vudec registrations, 3800 students of the total of 8000 were registered in the Faculty of Education. This was followed by 1800 students in the Faculty of Arts, 1500 in the Faculty of Economic Sciences, 500 in the Faculty of Natural Sciences and 400 students in the Faculty of Law. Due to the focus on upgrading under-qualified teachers, the majority of students were registered in undergraduate programmes. For the 2003 academic year only 1800 students were enrolled for postgraduate studies. Of this number, 1400 were registered for the honours degree in Education, 350 for honours degrees spread over the rest of the humanities and 50 enrolments represented Master's studies in Education (Vista MIS 2003).

These enrolment figures reiterated the situation found in all historically disadvantaged institutions (HDI's), namely, an overrepresentation in the lower level programmes of the humanities with very low participation rates in types and levels of registration in the natural science programmes (NCHE 1996, 13). Another perceivable characteristic of all HDIs, also noticeable at Vudec, was the significant decrease in student numbers since 1994. Vudec had a total student number of 18 000 in 1994. In 1998 this figure had decreased to 10000 with a further decrease to 8000 students in 2003 (Vista MIS 2003). Elliot $(2005,72)$ argues that the reason for government's prolonged policy on mergers is to be found in the anticipated massification of higher education that was expected after 1994. If this massification had occurred, it would have resulted in a shortage of physical capacity. However, as supported by Vudec's decreased enrolment figures the envisaged massification did not materialise on account of factors relating to student migration and decreased matric pass rates.

The typical Vudec student was a practising black teacher with a minimum of five years' teaching experience. The majority of Vudec students were initially in the possession of a three-year Teacher's Diploma obtained from various teachertraining colleges in South Africa. The average age of a typical VUDEC student was 34 years and 60 per cent of students were female. The majority of students resided in the Limpopo Province, followed by Gauteng, KwaZulu-Natal and Mpumalanga. A significant number of students in the Faculty of Education also lived in Oshakati, Namibia. Since the majority of VUDEC students resided in the 
Limpopo Province, the largest group of VUDEC students spoke Northern Sotho. Only 3 per cent of all Vudec students had e-mail facilities in 2003 (Vista MIS 2003).

With regard to academic competencies many Vudec students were underprepared for higher education and were aware that they would not have survived nor even been accepted at other higher education institutions. Students were desperate for higher education and the option of lower access requirements enabled many to complete their qualifications eventually after a longer stay in the system. Notwithstanding the academic weaknesses of these students, brilliant and loyal students chose Vudec as their alma mater and progressed successfully along the academic developmental ladder of initial certificate, advanced diploma, degree studies and eventually postgraduate studies. Uniformly considered, however, a significant proportion of students approached Vudec as 'a university of last resort . . . and the sad part is that they pass enough first year modules to carry on with the second year, but many of them seriously battle to pass a degree' (Vudec academic). Unfortunately, access equity with resulting migration tendencies changed the image of black universities, including Vudec, to that of veritable social welfare nets for academically failing and financially needy students (Jansen 2005, 6). Merging would indeed help to address this predicament and signify valuable gains for able students, as articulated by a Vudec honours student:

I think the myth surrounding the Vudec institution needs to be cleared. They say Vista students are not quality students. As a result I cannot get employment. So maybe we need to merge so that this myth could get the deathblow.

Within the equity context of an impartial and fair provision of opportunities and privileges (NCHE 1996, 41), a pivotal question relates to the destiny of students in need of special guidance with regard to academic development. An academic expressed this concern as follows:

Vudec has students with special needs in the sense of attention and one will have to put structures in place to prevent those students from just disappearing due to not getting personal attention and constant availability of lecturers.

The conundrum as to the destiny of these at risk students relates to the fact that they are practising teachers and as such focused on 'mobilising the potential of the [in many cases, neglected] human capacity of the country, for the common good' (NCHE 1996, 42). Failure to address the developmental needs of these teachers would not only imply an equity loss for many Vudec students, but also a merit loss for the teaching profession in terms of failing to improve the teaching skills of practising teachers.

\section{Academic staff profile}

In 2003 Vudec had 75 academic staff members of which 51 were female, 30 black 
and the majority in the age group of 45 to 60 (Vista MIS 2003). Although the decrease of white dominance was significant from the 1998 figures that posed 20 black and 60 white academics (Vista MIS 2003), the successful pursuit of racial representation was challenging at Vudec as elsewhere in the country 'due to the heaven of job possibilities available to black academics . . . they are continuously offered better salaries elsewhere' (Vudec academic).

The initial exclusive offering of certificates and diplomas to under-qualified teachers until market saturation was reached (Van der Merwe 1997), characterised Vudec as a college of advanced education (CAE) similar to the CAEs in Britain and Australia. Typical of CAEs is a high value placed on teaching with less emphasis on research (Harman 2002, 98). This was reflected in the research outputs of Vudec academic staff that compared most unfavourably to the outputs of UNISA. For the six-year period of 1998 to 2003 only 44 units were published at Vudec (Vista MIS 2003) compared to the 395 units for 2003 and 471 units for 2004 of UNISA (UNISA MIS 2005). However, considering the debilitating conditions brought about by the announcement of the unbundling of Vista University (Hay et al. 2001, 128) and 'the perception that academics would not be promoted on research outputs because Vudec was only a tertiary college that specialised in teacher training' (Vudec academic), the modest research output is worth noting.

A classic university is characterised by a strong research culture and the featuring of research as key criterion for scholarly recognition and promotion (Harman 2002, 98). This is the perception of UNISA and is substantiated by its research output. Thus, many academics at Vudec anticipated gains from joining a research-oriented environment. A Vudec academic articulated this anticipation as follows:

I am looking forward to be a "running stream" academic as opposed to a "stagnant pond" one. I am excited about the possibility of being provided with opportunities to conduct research within an environment that places a high premium on research output.

\section{Social responsibility and Vudec's unique character}

Although Vudec academics contributed to a lesser extent to research output, their commitment to teaching and community service was highly commended. With particular reference to the upgrading of under-qualified teachers in the traditionally disadvantaged communities, Vudec fulfilled a significant role in that 'many teachers in black schools are Vudec graduates and they tend to have engendered a loyalty to Vudec by having encouraged colleagues to study through us' (Vudec manager).

The exceptional quality of caring and the active interaction between lecturers 
and students at Vudec was possible due to Vudec's size, which resulted in the accentuation of the human element and the students' expectations of personalised attention. A Vudec manager captured this unique Vudec culture as follows:

Vudec brings lecturers, administration and students closer to one another. It emphasises the human element where students feel the warmth and the presence of their lecturers and the administration. In this regard Vudec is bringing along certain expectations, a culture of caring, a culture of sensitivity to the specific needs of their students. Vudec is bringing along a culture of staff that is committed and well converted in certain experiences, which is really an advantage when one's work is to improve the quality of a teacher.

Vudec indeed provided a special service to a special target market. This related to a sympathetic and informed approach to the well-being of practising black teachers who were engaged in the upgrading of their teaching knowledge and skills and who needed extra academic support and guidance. On account of both equity and merit, a sensitisation to the needs of this specific target group should be accommodated within the merger. How this should be achieved while taking cognisance of globalisation imperatives requires further investigation.

\section{GAINS AND LOSSES FOR VUDEC WITH MERGING}

For Vudec staff a significant gain resides with the possibility of enhancing their research profiles within an environment characterised by a strong research culture. In its mission statement UNISA proclaims the undertaking of 'research and knowledge development guided by integrity, quality and rigour' (UNISA 2015). This is manifested in college, school and departmental plans to stimulate individual goal setting. Within each department, research mentors assist individual members with research activities. This is accompanied by a series of workshops organised on institutional level to stimulate research activity and commitment. Incentives are in place for professional development and inviting rewards are granted for research outputs. The merger motive of research efficiency within a global context of 'academic capitalism' is indeed a wonderful gain for Vudec academics.

Significant gains for Vudec students reside in the higher status, better and broader programme offerings and advanced resources made available by the merger. In its mission statement UNISA promises to 'address the needs of a diverse learner profile by offering relevant learner support, facilitated by appropriate information and communications technology' (UNISA 2015). In this regard, the availability of UNISA's complete library collection for use by competent students, the efficiency of the administrative capacity to despatch study material punctually and the sophistication of the UNISA facilities to students with on-line facilities are impeccable. Apart from achieving equity of access with these gains, merit resides 
in the equity of opportunity and the equity of adequacy to Vudec students to utilise more and better opportunities for career development and to improve their teaching skills.

However, a detrimental loss for Vudec students resides in the possibility that the huge and powerful UNISA will afford little room for seriously disadvantaged students who formed a large proportion of the total Vudec student corps. Although higher education should help erode the inherited socially structural inequities by providing opportunities for social advancement through equity of access and opportunity (CHE 2000, 12), this should be complemented by a concern for equity of outcomes to avoid a 'revolving door' syndrome of high failure and dropout rates (Education White Paper 3 1997, 22). For the period 2000 to 2002, for example, the number of university students failing in South Africa added up to 50 per cent of the total of enrolments resulting in an annual state expense of R1.5 milliard (Beeld 14 May 2005, 4), which is not complementary to a global sphere dominance of merit outcomes.

In its mission statement UNISA proclaims to be 'accessible to all learners, specifically those on the African continent, and the marginalised, by way of a barrier-free environment, while responding to the needs of the global market' (UNISA 2005). Based on this proposition the under-qualified teacher students of Vudec should be well catered for. However, for the year 2004 (the first year of incorporation), the number of ex-Vudec enrolments at UNISA amounted to 4635 students (UNISA MIS 2005). This number included pipeline students who were busy completing their Vudec qualifications as well as ex-Vudec students who were enrolling for further UNISA qualifications. Considered against Vudec's enrolment of 8000 students for the year 2003 and the tendency of an enrolment decrease of 9 per cent per year since 1994 (Vista MIS 2003), this still constitutes a significant loss of 33 per cent students for the first year of merged incorporation. Unfortunately, since 2004 no statistics are available with regard to new registrations of ex-Vudec students due to the unitary character of the merger and the obliteration of the Vudec institution (UNISA MIS 2006). One can assume, however, that the proportion of ex-Vudec students that disappeared from the merged landscape in 2004 would be the academically needy ones.

The probable disappearance of the under-prepared Vudec students signifies an obvious failure for equity, but also a subtle loss for merit - increasing the competencies of black practising teachers for the sake of the common good embodies a merit motive. The 'disappearing' students teach the previously disadvantaged youth who form part of South African society and who should be prepared for participation in a global knowledge based economy. It is therefore argued that, on account of merit, Vudec's sensitised service to these students should be accommodated within the merger. Investigating sustainable measures for the accomplishment of such accommodation should indeed receive high priority on an institutional level. 


\section{CONCLUSION}

The 21 years of Vudec's constructive service provision to practising black teachers justified the recording of its existence within the annals of South African higher education history. Merging with UNISA resulted in significant gains for Vudec students and staff on account of career development possibilities, higher status, broader programme offerings and advanced resources. In this regard the obliteration of the Vudec culture represents no loss. The elimination of the Vudec culture, however, is accompanied by a disappearance of that segment of Vudec students who were under-prepared for higher education. Within a worldwide sphere of global economy competitiveness, this seems to resemble a victory of merit over equity. However, it represents neither one of the two imperatives with merging because the disappearing student corps are practising teachers instructing previously disadvantaged learners who depend on a good education for participation in a global knowledge based economy. It is therefore important that Vudec's sensitised service to these students be accommodated in the Vudec/ UNISA/TSA merger to ensure not only an equity achievement, but even more so, a merit accomplishment. Measures by means of which this accommodation should be arranged and viably sustained need to be constantly considered for the sake of 'the common good' (NCHE 1996, 42).

\section{REFERENCES}

Beeld. 2005. Maak plan met erge gedruip, sê minister. 14 May:4.

Botha, M. M. 2001. Models for mergers in higher education. South African Journal of Education 21 (4): 273-280.

Cohen, L., L. Manion and K. Morrison. Eds. 2002. Research methods in education. London: Routledge Falmer.

Christie, P. 1996. Globalisation and the curriculum: Proposals for the integration of education and training in South Africa. International Journal of Educational Development 16 (4): $407-$ 416.

CHE, see Council on Higher Education.

Council on Higher Education. 2000. Towards a new higher education landscape: Meeting the equity, quality and social development imperatives of South Africa in the $21^{\text {st }}$ Century. Report of the Shape and Size of Higher Education Task Team. Pretoria: Department of Education.

Curri, G. 2002. Reality versus perception: Restructuring tertiary education and institutional orgnisational change - a case study. Higher Education 44:133-151.

De Vos, A. S. 1998. Research at grass roots. A primer for the caring professions. Pretoria: Van Schaik.

Department of Education. 2002. The transformation and reconstruction of the higher education system. 30 May. Pretoria: Government Printers.

DoE, see Department of Education.Education White Paper 3. 1997. A programme for the transformation of higher education. July. Pretoria: Department of Education.

Elliot, J. 2005. Merging right: Questions of access and merit in South African higher education reform, 1994-2002. Perspectives in Education 23 (1): 69-76. 
Goedegebuure, L. C. J. 1992. Mergers in higher education: A Comparative Perspective. Utrecht: Lemma.

Harman, K. M. 2002. Merging divergent campus cultures into coherent educational communities: Challenges for higher education leaders. Higher Education 44 (1): 91-114.

Harman, K. and L. Meek. Eds. 2002. Introduction to special issue: 'Merger revisited: international perspectives on mergers in higher education'. Higher Education 44:1-4.

Hay, H. R., M. Fourie and J. F. Hay. Eds. 2001. Are institutional combinations, mergers or amalgamation the answer? An investigation into staff perceptions. South African Journal of Higher Education 15 (1): 100-108.

Hughes, P. 1995. Internationalisation of education and curricula for the twenty-first century. Educational Research and Perspectives 22 (2): 171-192.

Jansen, J. D. 2002. Mergers in higher education. Lessons learned in transitional texts. Pretoria: UNISA Press.

Jansen, J. D. 2003. Mergers in South African higher education: Theorising change in transitional contexts. Politikon 30 (1): 27-50.

Jansen, J. D. 2004. Race and education after ten years. Perspectives in Education 22 (4): 117128.

Jansen, J. D. 2005. The politics and poetics of institutional transformation: The University of Pretoria as a case in point. Paper presented at Intellectual Crossroads: An interdisciplinary seminar series for the entire Humanities, Education and Law. University of Pretoria.

Johnson, J. M. 2002. In-depth interviewing. In Handbook of interview research: Context and method, ed. J. F. Gubrium and J. A. Holstein. London: Sage.

Kenway, J. 1996. The information superhighway and post-modernity: The social promise and the social price. Comparative Education 32 (2): 217-231.

Lang, D. W. 2002. There are mergers, and there are mergers: The forms of inter-institutional combination. Higher Education Management and Policy 14 (1): 11-50.

Louw, W. J. 1997. Die idee van die universiteit vir die 21ste eeu - 'n Suid-Afrikaanse perspektief. Pedagogiekjoernaal 18 (1): 25-56.

National Commission on Higher Education. 1996. A framework for transformation. April. Pretoria: Department of Education.

National Plan on Higher Education. 2001. Pretoria: Ministry of Education.NCHE, see National Commission on Higher Education.

Norgard, J. D. and O. Skodvin. Eds. 2002. The importance of geography and culture in mergers: A Norwegian institutional case study. Higher Education 44:73-90.

NPHE, see National Plan on Higher Education.

Ntshoe, I. M. 2003. The political economy of access and equitable allocation of resources to higher education. International Journal of Educational Development 23:381-398.

- 2004. Higher education and training policy and practice in South Africa: impacts of global privatisation, quasi-marketisation and new managerialism. International Journal of Educational Development 24:137-154.

Patton, M. Q. 2001. Qualitative research and evaluation methods. California: Sage.

Reddy, J. 2000. Regional consortia, partnerships, mergers and their implications for the transformation of the South African higher education system. South African Journal of Higher Education 14 (1): 79-87.

Republic of South Africa. 1997. Higher Education Act no 101 of 1997. Government Gazette no 18515. Pretoria: Government Printers.

RSA, see Republic of South Africa. 
Sehoole, M. T. C. 2005. The politics of mergers in higher education in South Africa. Higher Education 50:159-179.

Struwig, F. W. and G. B. Stead. Eds. 2001. Planning, designing and reporting research. Cape Town: Masker Miller Longman.

University of South Africa Management Information System. 2005. Pretoria: UNISA Muckleneuk Campus.

. 2006. Pretoria: UNISA Muckleneuk Campus.

UNISA MIS, see University of South Africa Management Information System.

UNISA. 2005. UNISA 2015: An agenda for transformation. Corporate Manual. Available online.

Van der Merwe, H. M. 1997. 'n Bepaling van studentebehoeftes by VUDEC. Vista Occasional Papers 5 (1): 58-69.

Vista University Calendar. 2003. An African university for economic and social development Part 1. Pretoria: Vista University.

Vista MIS, see Vista University Management Information System.

Vista University Management Information System. 2003. Pretoria: Vista University Central Campus.

Weber, E. 2002. Shifting to the right: the evolution of equity in the South African government's developmental and education policies, 1990-1999. Comparative Education Review 46 (3): 261-290.

Wyngaard, A. and C. Kapp. Eds. 2004. Rethinking and re-imagining mergers in further and higher education: a human perspective. South African Journal of Higher Education 18 (1): $185-201$ 